\title{
COMPARISON OF MULTI-SCALE DIGITAL ELEVATION MODELS FOR DEFINING WATERWAYS AND CATCHMENTS OVER LARGE AREAS
}

\author{
Bruce Harris ${ }^{1}, 2$ Kevin McDougall1, Michael Barry² \\ ${ }^{1}$ University of Southern Queensland \\ ${ }^{2}$ BMT WBM Pty Ltd.
}

KEY WORDS: Digital Elevation Models, Waterways, Geographic Information Systems, Regional Areas, Lidar

\begin{abstract}
:
Digital Elevation Models (DEMs) allow for the efficient and consistent creation of waterways and catchment boundaries over large areas. Studies of waterway delineation from DEMs are usually undertaken over small or single catchment areas due to the nature of the problems being investigated. Improvements in Geographic Information Systems (GIS) techniques, software, hardware and data allow for analysis of larger data sets and also facilitate a consistent tool for the creation and analysis of waterways over extensive areas. However, rarely are they developed over large regional areas because of the lack of available raw data sets and the amount of work required to create the underlying DEMs. This paper examines definition of waterways and catchments over an area of approximately $25,000 \mathrm{~km}^{2}$ to establish the optimal DEM scale required for waterway delineation over large regional projects.
\end{abstract}

The comparative study analysed multi-scale DEMs over two test areas (Wivenhoe catchment, $543 \mathrm{~km}^{2}$ and a detailed $13 \mathrm{~km}{ }^{2}$ within the Wivenhoe catchment) including various data types, scales, quality, and variable catchment input parameters. Historic and available DEM data was compared to high resolution Lidar based DEMs to assess variations in the formation of stream networks. The results identified that, particularly in areas of high elevation change, DEMs at $20 \mathrm{~m}$ cell size created from broad scale 1:25,000 data (combined with more detailed data or manual delineation in flat areas) are adequate for the creation of waterways and catchments at a regional scale.

\section{INTRODUCTION}

Rapid population increase in South East Queensland (SEQ), Australia has placed significant demands on the ecosystems of the region. This has led to the need for a better understanding of the networks of waterways and catchments in the region. Therefore, a consistent regional digital elevation model grid interval for the establishment of catchments and waterways is required.

Whilst field mapping is acknowledged as the most accurate way to determine waterways, this is often impractical, especially for large catchments (Tarboton et al. 2001). In the 1960 s, with the advent of computer technology, researchers began to see the potential of digital technology to perform this task automatically by computers (Garbrecht and Martz, 2003). Martz et al. 2003 identified that research over the past decade demonstrated the feasibility of extracting topographic information of hydrological interest directly from DEMs. As such, catchments and flow paths are now delineated automatically using GIS and DEMs of the surface terrain (Joseph 2008). Martz and Garbrecht, 2003 attributed this to the availability of DEM data and software products and the need for landscape derived data.

A DEM is indispensable for many analyses such as topographic feature extraction, but before such analyses, accuracy of the DEM must be discussed (Takagi 1997). Issues of error, accuracy, scale, spatial extent and resolution should be considered (Zerger 1999). Increasing surface resolution allowed an increase in the precision of stream channel modelling (Mouton 2005). Accuracy of a DEM is represented by spatial resolution and height, in this work the accuracy was evaluated according to spatial resolution (Takagi 1997). Wang et al. 1998 investigated comparisons between 1:250,000 and $1: 24,000$ and noted that the estimation of the mean gradient parameters based on the $250 \mathrm{~K}$ DEMs seems to improve with increasing terrain complexity. Results showed that superior estimations are produced from the 24K DEMs (Wang et al. 1998).

The paper investigates the creation of multi-scale spatial resolution DEMs with at worst 1:25,000 data to determine the most appropriate grid interval for waterway and catchment delineation over large areas such as SEQ. The issues of overall DEM accuracy and the consequential impacts on the production of hydrological networks are explored. The two principal areas are discussed in this paper are: 1. Assessing the most suitable DEM grid size for regional waterway construction $(90,20$ or $5 \mathrm{~m})$ and 2 . Catchment input resolutions $\left(1.0,0.5,0.25\right.$ and $\left.0.1 \mathrm{~km}^{2}\right)$. Catchment input resolutions define detail of the created waterway network. A conclusion is reached regarding the most suitable grid interval for a large regional project.

\section{METHODS}

It is typically desirable that a consistent methodology and associated dataset of waterways be developed for creation of new datasets. The aim and scope of this work was to develop 
an improved stream ordered waterway network for SEQ, based on a suitable (and therefore improved) DEM of the area. The improved DEM allowed for the development of a GIS data set of the waterways network across the region (See Figure 1).

\subsection{Study Area}

The overall South East Queensland (SEQ) study area was investigated in response to the need for waterways and catchments information by a range of stake holders including local, state and federal government, community groups and industry. SEQ covers an area of approximately $25,000 \mathrm{~km}^{2}$ and ranges in elevation from sea level to almost $1400 \mathrm{~m}$, stretching from Noosa Heads in the north to Tweed Heads in the south and from Moreton Bay in the east to Toowoomba in the west (approximately 250 kilometres north to south and 150 kilometres east to west) (See Figure 1).

A necessary stage in developing a suitable $25,000 \mathrm{~km}^{2}$ DEM was to develop and test DEMs over smaller areas for initial to assess the impacts of DEM accuracy and grid spacing. As a consequence, a detailed investigation was undertaken using $90 \mathrm{~m}, 20 \mathrm{~m}$ and $5 \mathrm{~m}$ DEM data in two assessment areas to identify the most appropriate DEM scale. The selection of the smaller study areas was based on the availability of various quality elevation data which were available over the larger regional area. The first detailed area chosen was the Wivenhoe catchment which is approximately $543 \mathrm{~km}^{2}$ and ranges in elevation from $25 \mathrm{~m}$ to almost $100 \mathrm{~m}$, stretching from Gallangowan in the north to Crows Nest in the south and from Somerset Dam in the east to Wutul in the west (approximately 100 kilometres north to south and 90 kilometres east to west).

The second area for detailed DEM assessment was a $13 \mathrm{~km}^{2}$ area within the Wivenhoe catchment. This area was chosen because of the availability of data and the variability in the terrain which was considered representative of the area. The area was limited in size due to Lidar data access/availability and the time required to process this type of information over a larger area. Elevation of the area ranged from $39 \mathrm{~m}$ to $227 \mathrm{~m}$.

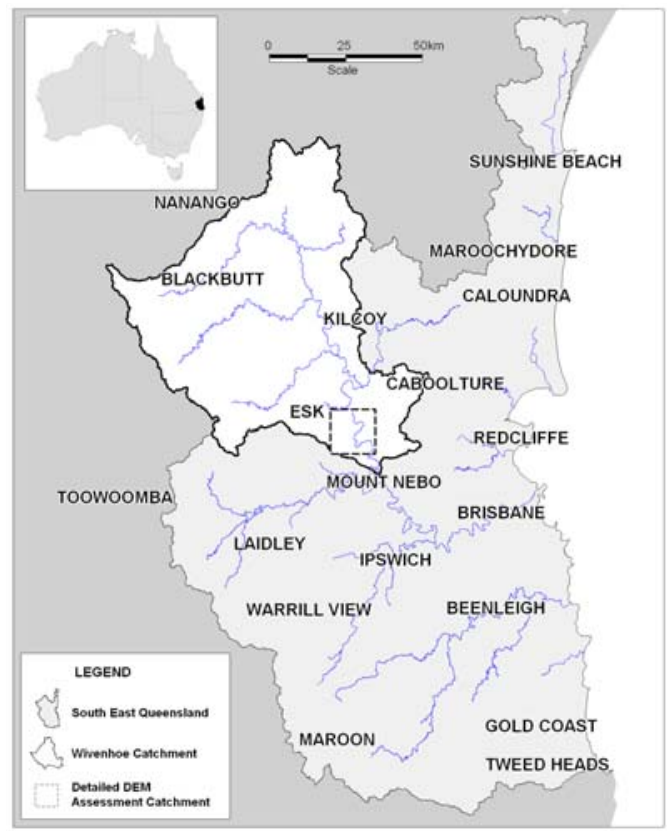

Figure 1. Study Areas

\subsection{Data Sources}

Relevant Federal, State and Local Government agencies were contacted to source and acquire applicable topographic data sets for the study area.

Three DEMs were analysed for this study, ranging from a $90 \mathrm{~m}$ DEM through to high resolution Lidar DEM information. Table 1, describes the available DEM information.

\begin{tabular}{|l|l|l|l|}
\hline Data & $90 \mathrm{~m}$ DEM & $20 \mathrm{~m}$ DEM & 5m Lidar DEM \\
\hline Source & $\begin{array}{l}\text { International } \\
\text { Centre for } \\
\text { Tropical } \\
\text { Agriculture }\end{array}$ & $\begin{array}{l}\text { Built from data } \\
\text { ranging from } \\
\text { Lidar through to } \\
5 \mathrm{~m} \text { contours }\end{array}$ & $\begin{array}{l}\text { AAMHatch and } \\
\text { Fugro Lidar data }\end{array}$ \\
\hline Coverage & SEQ & SEQ & $\begin{array}{l}\text { Parts of Coastal } \\
\text { SEQ }\end{array}$ \\
\hline
\end{tabular}

Table 1. Available DEM Data

The $90 \mathrm{~m}$ DEM was a pre-processed grid, $20 \mathrm{~m}$ and $5 \mathrm{~m}$ DEMs were built for this study. The $20 \mathrm{~m}$ DEM required the most processing, it being created from combination of data as described in Table 1. Eighteen Local and State governments were approached and supplied the best available data from their areas. These data ranged from highly accurate Lidar data to at worst $5 \mathrm{~m}$ contour data (See Figure 2).



Lidar data

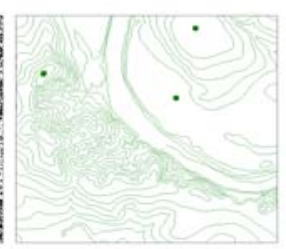

$5 \mathrm{~m}$ contours
Figure 2. Examples of Raw Data

Figure 3, displays the three processed DEMs in the $13 \mathrm{~km}^{2}$ detailed assessment area.

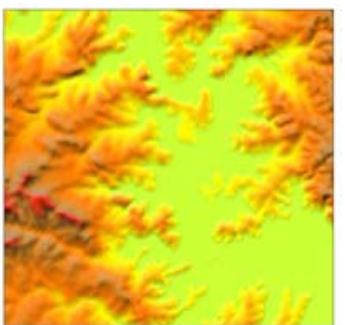

90






Figure 3. 90, 20 and $5 \mathrm{~m}$ DEMs 


\subsection{Data Development and Processing}

DEMs for this study were built and analysed with a variety of Civil Design and Surface Modelling software. They were built/processed using a common projection system, MGA94, Zone 56. The overall Data Development Process is described in Figure 5.

The 20m DEM was the most difficult to build (see Figure 4), it required the assembly, prioritising and merging of various quality available State and Local Government data sets (such as that provided by land-based surveys, photogrammetry, lidar etc.) to build a regional DEM. Assessing the quality of available data, and therefore priority of the data in the merging process required extensive analysis and time. After some initial processing and ground truthing of the available DEM information, 'edge matching' (to ensure a seamless join between data sets) of the $20 \mathrm{~m}$ grid resolution DEM was completed. Areas not covered by suitably detailed data were filled with $5 \mathrm{~m}$ contour data from the Department of Energy and Resource Management.

Difficulties experienced due to the resolution of the 20m DEM in very flat areas (e.g. canal estates) were overcome by digitising the required waterways from satellite imagery/aerial photography and adding attributes to match the waterways generated by the software.



Figure 4. SEQ $20 \mathrm{~m} \mathrm{DEM}$

The 90,20 and $5 \mathrm{~m} \mathrm{(5m} \mathrm{in} \mathrm{the} 13 \mathrm{~km}^{2}$ detailed assessment area) DEMs were "pit filled". This process ensured pits (or depressions) in the DEM are filled using D8 (Tarboton 1997) methodology to allow water to flow across the surface of the DEM. D8 pit filling allows for flow from each cell within a DEM (or grid). Each grid cell is allowed to flow to a cell that surrounds it. Lower cells (those that are lower than the eight surrounding them) are filled to enable flow. When used with high-resolution DEMs, D8 proved to be sufficient when compared to more complicated and process demanding algorithms (Mouton 2005).

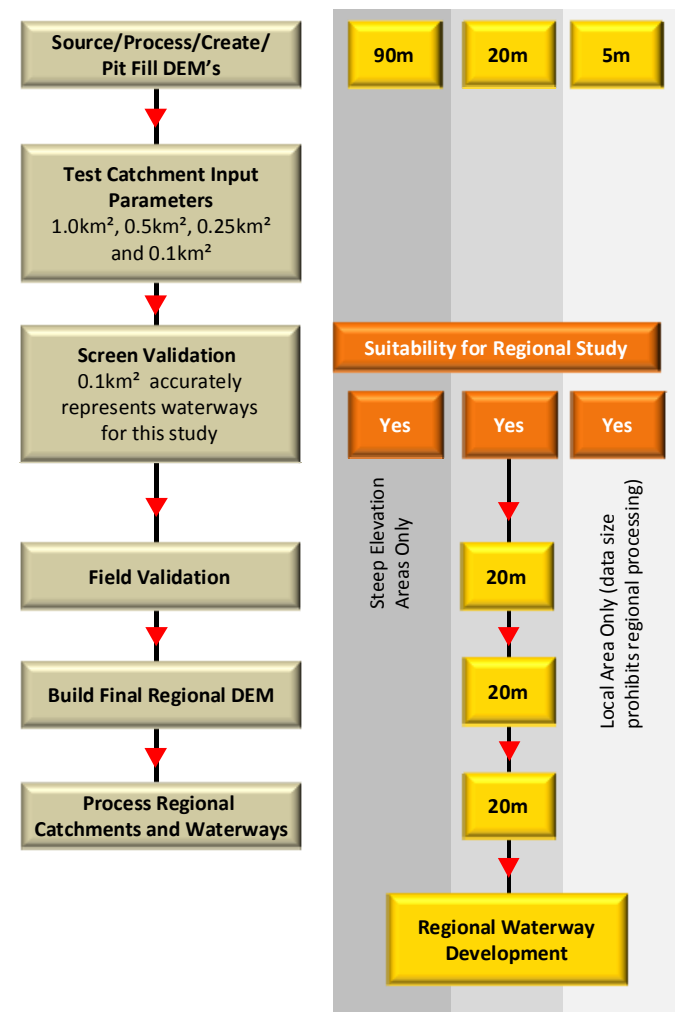

Figure 5. Data Development Process

Catchments and waterways were delineated from the DEMs using various input catchment areas to test the appropriate input catchment resolution area for accurate waterway creation. The different input catchment resolution can be used to specify the accurate starting point of the waterway polylines. The catchment input resolution defines the smallest area that the software will create a waterway network. The smaller the area, the more detailed the waterways will be (as displayed in Figures 7, 8 and 9). Catchment input resolution was a critical component of this study defining the commencement of a first order waterway. Small input catchment areas will define more first order streams and increase the network detail and therefore lengths and locations of waterways, and vice versa.

To ensure accurate representation of streams in SEQ, sample stream order maps were created at four first order catchment input definitions, namely $1.0 \mathrm{~km}^{2}, 0.5 \mathrm{~km}^{2}, 0.25 \mathrm{~km}^{2}$ and $0.1 \mathrm{~km}^{2}$ (Figure 7, 8 and 9). These criteria were applied to the three different grid sized DEMs.

This data was digitally checked with satellite imagery and aerial photography for accuracy. The $0.1 \mathrm{~km}^{2}$ catchment input area was the preferred catchment definition, providing both the greatest level of detail and best fit with detailed local drainage network data over a range of elevation landscapes.

\subsection{Field Verification}

After initial the desktop review process, data derived using the $0.1 \mathrm{~km}^{2}$ first order stream catchment definition using the $20 \mathrm{~m}$ DEM was considered to be most suitable for field ground truthing. The ground truthing exercise involved travelling through selected areas to check and record information on the waterways using the various data including the $20 \mathrm{~m}$ derived information. 
The locations and descriptions of actual waterways were compared to the computer generated $0.1 \mathrm{~km}^{2}$ (along with samples of the other input definitions) stream order network to further assess the accuracy of the stream location and the appropriateness of the stream order number. The areas tested were selected to provide examples of varying terrain and land uses, such as, small and steep catchment, upland rural catchment, lowland rural catchment, and urban coastal plain.

\section{RESULTS}

\subsection{DEM Grid Size Comparisons}

Results from the various size DEMs identified variations in the quality of the output data. The larger the grid size of the DEM, the greater the deterioration in the waterway networks as shown in Figure 5.

The different waterways outputs were compared individually with aerial imagery to ascertain the degree of variability from actual stream locations. Data derived from the 90m DEM was found to be unsuitable, simply based on viewing digitally the extra amount of waterways in the flatter areas and the horizontal accuracy of the waterways. Further digital validation of the waterways created from the $20 \mathrm{~m}$ and $5 \mathrm{~m}$ DEMs enabled them to be considered to be suitable for further analysis. Figure 6 displays variations in derived data from the DEMs.


$5 \mathrm{~m}$

Figure 6. Data derived from available DEMs $0.1 \mathrm{~km}^{2}$ input catchment input

Example results from various sized DEMs in the detailed 13 $\mathrm{km}^{2}$ area using a $0.1 \mathrm{~km}^{2}$ catchment input resolution are displayed in Table 2,

\begin{tabular}{|l|l|l|l|}
\hline & $90 \mathrm{~m}$ DEM & $20 \mathrm{~m}$ DEM & $\begin{array}{l}5 \mathrm{~m} \text { Lidar } \\
\text { DEM }\end{array}$ \\
\hline $\begin{array}{l}\text { Total length of } \\
\text { waterways }\end{array}$ & 391.8 & 331.12 & 351.17 \\
\hline $\begin{array}{l}\text { Stream Order 1 } \\
\text { waterways }\end{array}$ & 218.53 & 158.02 & 167.71 \\
\hline $\begin{array}{l}\text { Stream Order 2 } \\
\text { waterways }\end{array}$ & 73.59 & 67.64 & 89.06 \\
\hline
\end{tabular}

Table 2. Data derived from sample area of available DEMs (See Figure 1 - Detailed DEM Assessment Area).

\subsection{Catchment Input Areas}

Figure 7, shows lengths of waterways generated from the $20 \mathrm{~m}$ DEM with various input catchment areas. The smaller the input area, the more waterways generated in the assessment area of the Wivenhoe Catchment.

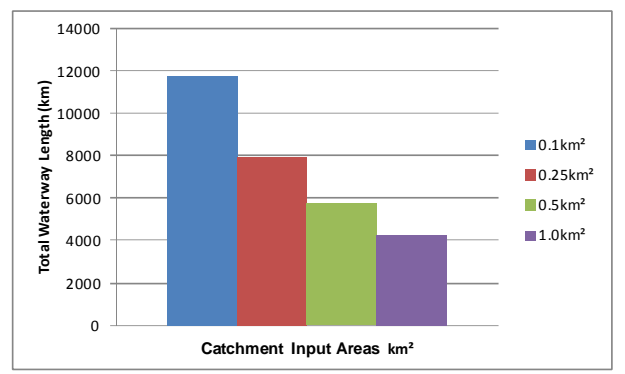

Figure 7. 20m DEM - Total Length of Waterways (Various Catchment Input Areas)

Figure 8, Stream Ordered Waterways 20m DEM (various catchment input areas) shows stream ordered waterways in the Wivenhoe Catchment. It displays a consistency of higher lengths of waterways for each stream order, within the various test catchment input resolutions.

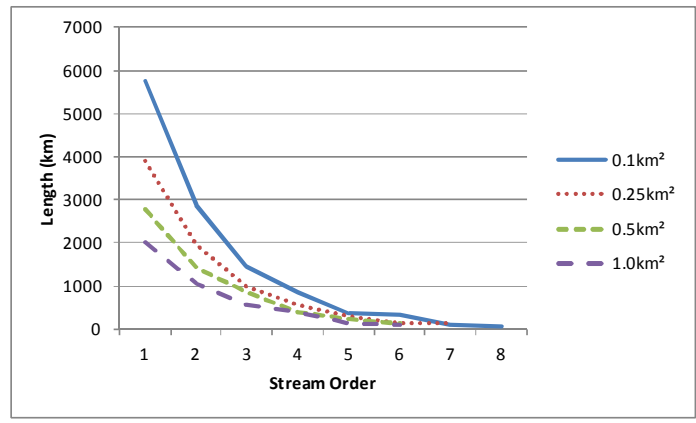

Figure 8. Stream Ordered Waterways 20m DEM (various catchment input areas)

Figure 9, Sample Stream Order Maps, Various Input Value displays waterways generated at different catchment input parameters.


Figure 9. Sample Stream Order Maps, Various Catchment Input Resolution Areas 


\subsection{Resizing DEMs}

The $20 \mathrm{~m}$ DEM was then resized to $30,50,75$ and $100 \mathrm{~m}$ to assess the impact on accuracy and location from the same data at different resolutions with a view to possibly being able to process the regional data in a more efficient manner. Figures 10, 11 and 12 display results derived from the various grid resolution DEMs.

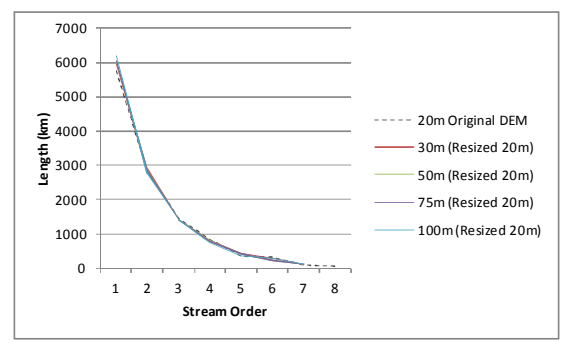

Figure 10. Overall waterways derived from 20m DEM resized to $30 \mathrm{~m}, 50 \mathrm{~m}$ and $75 \mathrm{~m}$ and $100 \mathrm{~m}$ DEMs



Figure 11. Stream Order 1 Waterways derived from 20m DEM resized to $30 \mathrm{~m}, 50 \mathrm{~m}$ and $75 \mathrm{~m}$ and $100 \mathrm{~m}$ DEMs

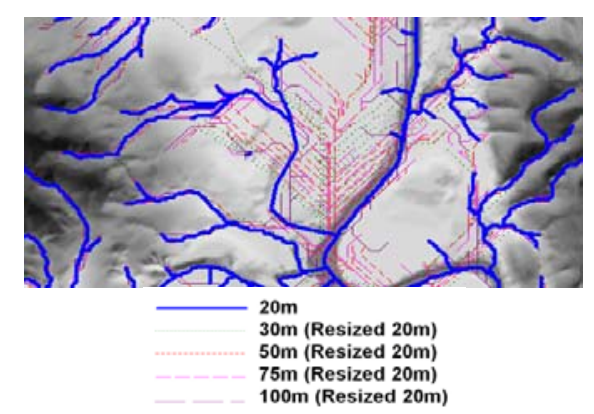

Figure 12. Waterways derived from 20m DEM resized to 30, 50 and 75 and $100 \mathrm{~m}$ DEMs

\section{DISCUSSION}

\subsection{Visual Similarities}

Visual similarities occur between data generated from various data sets at different resolutions with various input resolutions. The $90 \mathrm{~m}$ DEM appears to be visually acceptable at a regional SEQ scale, however it was less than suitable when used in a smaller catchment area (See Figure 6).

\subsection{Grid Size}

Higher and lower resolution grids can deliver an increase in the length of waterways. Table 2 gives an example of this. More waterways were derived from the higher resolution $5 \mathrm{~m}$ DEM because of its detail and lower resolution 90m DEM because of its flatness, creating extra stream order 1 waterways in both DEMs. The 90 and 5m DEMs giving what could be considered inaccurate results for this study given the results were to be used to assess lengths of potential loss of waterways or waterways that may require remediation. The 5 and $90 \mathrm{~m}$ DEM derived waterways giving an over inflated number of the stream ordered waterways for this work.

In areas of steep slope elevation of the DEMs the grid size has less impact on the location of waterways. The vertical elevation accuracy is less important than horizontal accuracy in defining waterway location in areas other than flat floodplains. Despite of the difference in the vertical accuracy of the $20 \mathrm{~m}$ DEM data was $90 \%$ of data $+/-5 \mathrm{~m}$ (Zerger 1999) compared with $+/-$ $0.15 \mathrm{~m}$ with the Lidar derived DEM, yet the ground truthed horizontal waterway location remained suitable at a regional scale.

Accuracy for high resolution DEMs created from suitable data (including original $20 \mathrm{~m}$ DEM) quickly falls away when the same data is resized to $30 \mathrm{~m}$ and beyond. Results from various grid sizes of the used data show that lengths of stream order 1 waterways are gained as the grid size is increased. The smoothness of the resized DEM allowing for the creation of extra lower order waterways (See Figures 10, 11 and 12). The length of waterways in the higher order decreases with the increased grid size. The increase in DEM size increases the length of stream order 1 (Figure 11) waterways and decreases the high order stream order 7 and 8 waterways. Whilst the overall lengths of waterways are similar when grids are resized (Figure 10), they provide a false account of waterway locations, horizontal accuracy falls away considerably as the grid size is changed (as displayed in Figure 12).

\subsection{Catchment Input Resolution}

Ground and screen testing of the DEM derived waterways found the $0.1 \mathrm{~km}^{2}$ DEM generated first order streams were generally shown to be the initial drainage lines in which water flow occurs, rather than just as a sheet flow across a surface.

\subsection{Lidar and "Traditional” DEM data}

Analysis in the detailed $13 \mathrm{~km}^{2}$ was conducted to assess how waterways would be derived if Lidar data was available over the entire study area.

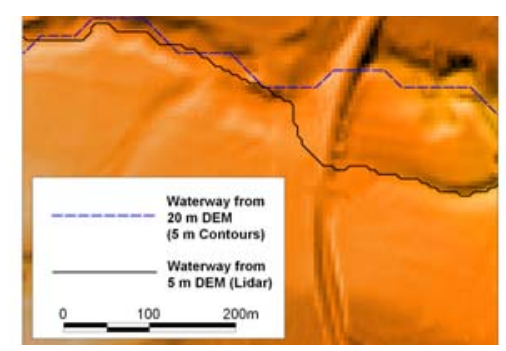

Figure 13. $20 \mathrm{~m}$ and $5 \mathrm{~m}$ DEM Waterway Locations

Investigation of the higher quality $20 \mathrm{~m}$ and $5 \mathrm{~m}$ DEMs revealed that whilst the Lidar derived $5 \mathrm{~m}$ DEM is of a higher standard, processing waterways from them will not always deliver the most accurate result. Figure 13 displays waterways created form the larger $20 \mathrm{~m}$ DEM is more likely to deliver a better located waterway results than the smaller (higher resolution) $5 \mathrm{~m}$ DEM. The higher resolution Lidar data displays road, bridges etc. as dams and therefore after pit filling the waterway can find an alternate route that may not necessarily be accurate. The results of the ground-truthing 
indicated that the streams produced using the $20 \mathrm{~m}$ DEM could accurately reproduce the stream order network observed in the field in areas of moderate to high relief (as displayed in Figure 6). As expected, in very flat areas (i.e. coastal floodplains) the output was not as accurate. At a regional scale the $20 \mathrm{~m}$ DEM waterways are a suitable way of locating lengths of waterways. The $5 \mathrm{~m}$ Lidar waterway lengths being a little longer based on every small bend in the waterway being defined.

The $20 \mathrm{~m}$ and $5 \mathrm{~m}$ Lidar DEMs provide suitable results for this study when extracting waterways and catchments. Lidar derived DEMs can be corrected to allow the creation of accurate data, but along with being less accessible and taking longer to process, also would take a long time to clean. Lidar DEMs have longer lengths of waterways which, particularly when the data is to be used to assess remediation of waterways would have little consequence. In fact the numbers may be skewed to be longer than the area to be remediated due to the extra bends in defined waterways. The $20 \mathrm{~m}$ data also has its problems; in flat areas it had to have better quality survey or Lidar information stitched in to assist with data delineation. Manually creating waterways in some of these regions can negate the need for time consuming updates to DEMs.

Overall, the data generated from the 20m DEM (which was available for the entire study area) provides for consistent waterway and catchment data at a resolution suitable for study of smaller, local catchments, shire and local areas. The $20 \mathrm{~m}$ DEM allowed for a suitable representation of waterways within an accuracy range required by the stakeholders

\section{CONCLUSIONS}

An improved, consistent regional DEM, and therefore improved waterways and catchments assists provide a consistent classification for data derived from it in far greater detail than previously existed for most localities. The new waterway network derived from the DEM is free of gaps in the line work that have often been present in existing stream network data. Streams and catchment characteristics can now be compared on a system that is standardised across SEQ.

Accuracy of DEMs is required to create suitable waterways and catchments. The methodology described in this paper allowed the evaluation of DEMs for catchment and waterway delineation for DEMs at various size input resolutions, various quality DEMs at different cell sizes. Lidar DEMs built from highly accurate information create high standard data, but roads, bridges and road cuttings create dams and waterways that do not normally exist. This is suitable over small areas but the cost and time to rectify over large areas is not viable. Also, at this time, Lidar data is not always available over these large areas. Availability, costs and processing times would make this type of data use impractical for large regional DEMs.

Study of DEMs at different resolutions, input parameters and from different sources reveals that a $20 \mathrm{~m}$ DEM created from mostly $5 \mathrm{~m}$ contours (with suitable high res data added in areas of low relief) is suitable for broadscale waterway and catchment delineation. The waterways and catchments for SEQ derived from the $20 \mathrm{~m}$ DEM allows users to view them at any scale and to also access attributes such as stream order, stream length, and stream elevation. The $20 \mathrm{~m}$ DEM was found to be most suitable over large areas based on availability, cost, processing time and accuracy of the output from it.

\section{REFERENCES}

Garbrecht, J., Martz, L.W. 2003. Assessing the Performance of Automated Watershed Segmentation from Digital Elevation Models. GIS for water Resources and Watershed Management. pp. 17-25.

Garbrecht, J., Martz, L.W., Starks, P.J. 2003. Technological Advances in Automated Land Surface Parameterization from Digital Elevation Models. GIS for water Resources and Watershed Management. pp. 207-217

Joseph, T. 2008, Catchment and Overland Flow Pathway Delineation using Lidar and GIS Grid Based Approach in Urban Stormwater and Sewer Network Models. New Zealand Water and Wastes Association Conference 2000. Christchurch, pp. 1-12.

Martz, L.W., Garbrecht, J., 2003. Channel Network Delineation and Watershed Segmentation in the TOPAZ Digital Landscape Analysis System. GIS for water Resources and Watershed Management. p. 10

Osorio, J., Wolfe, M.L., Heatwole, C., Benham, B., Cardenas, A. 2007. Comparison of watershed boundaries derived from SRTM and ASTER digital elevation. 2007 ASABE Annual International Meeting. p. 2.

Tarboton, D. G. (1997). A New Method for the Determination of Flow Directions and Upslope Areas in Grid Elevation Models. A New Method for the Determination of Flow Directions and Upslope Areas in Grid Elevation Models. 33(2): 2.

Tarboton, D. G., Ames, D. P. 2001. Advances in the Mapping of Flow Networks from Digital Elevation Data. World Water and Environmental Resources Congress, Orlando, Florida, pp. $1-10$.

Joseph, T. (2008). Catchment and Overland Flow Pathway Delineation using Lidar and GIS Grid Based Approch in Urban Stormwater and Sewer Network Models. New Zealand Water and Wastes Association Conference 2007. Christchurch: 1-12.

Mouton, A. (2005). Generating Stream Maps Using LiDAR Derived Digital Elevation Models and 10-m USGS DEM. Washington, University of Washington.

Takagi, M. (1997). Accuaracy of Digital Elevation Model According to Spatial Resolution. ISPRS Commission IV Symposium - Between Visions and Applications. T. G. Englich Fritch, M. Sester, M. Stuttgart, IAPRS. 32: 1.

Tarboton, D. G. (1997). "A New Method for the Determination of Flow Directions and Upslope Areas in Grid Elevation Models." A New Method for the Determination of Flow Directions and Upslope Areas in Grid Elevation Models 33(2): 2.

Wang, X. and Z. Yin (1998). "A comparison of drainage networks derived from digital elevation models at two scales." Journal of Hydrology 210(1-4): 221-241.

Zerger, A. (1999). "Digital Elevation Modelling for Natural Hazard Risk Assessment." Australian Journal of Emergency Management: 5. 